\title{
Introduction
}

\section{Tourism and Applied Anthropology in Theory and Praxis}

\author{
Kevin A. Yelvington
}

Academic social and cultural anthropology concerned with tourism has provided thick descriptions of the tourist exchange in a number of contexts, with exegeses devoted to illustrate the sexualized Other, the appropriation of landscape, the uses of the past in the present, and the detrimental effects of tourism structures on the 'host' communities. It has shown us how pilgrimages, beaches and museums become iconic and fetishized in the tourist's gaze, how the landscape is appropriated and a geographical space is turned into a cultural place. Yet, for applied anthropologists concerned with the impacts of the world's largest industry on local 'toured' populations and how the (unequal) tourism exchange is (unequally) constituted through material and symbolic historical processes, do the theories generated in the academic tradition provide a use-value? Do those anthropologists engaged in community-centred methods such as participatory action research, and working in theoretical traditions through praxis, approach their subject in the same ways as their nonapplied anthropological counterparts? Indeed, what can applied anthropologists, as such, and the consideration of applied projects, contribute to theory in anthropological research on tourism more generally?

This special issue draws upon applied anthropological practitioners (although most of them are based in academic settings) to understand the state of their art. The topics contained therein include the uses of tourism development projects in solving the problems of inter-communal violence; the politics of representation as well as understandings of audiences and media-based constructions of the toured'; and the ways in which the state and capital intersect in the development of tourism policy. These articles are all presented with the aim to provide critical models, be they more 'theoretical' or 'practical', for applied anthropology.

Some applied anthropologists in the critical tradition have embraced the notion of praxis as a model of and for community engagement (e.g., Gow 1993; Kozaitis 2000; Singer 1994; Warry 1992). Praxis - defined loosely here as theoretically informed practice - of course has a long history in Western philosophy and politics, and includes a variety of thinkers from Aristotle to Bacon to Kant to Hegel to Marx to Gramsci to Sartre. Although conceived of through the years in various ways, those anthropologists who are conscious inheritors of this tradition see praxis as simultaneously a partially reflexively revealed description of what they are doing in their anthropological practice, a theoretical idiom, an inspiration for their methodologies and their unit of analysis. That is, applied anthropologists are doing praxis when they are studying the praxis of community members, interviewees, cultural consultants - that is, the people from whom they learn. At the same time, anthropological praxis entails a critical-(re)iterative process of theoretical development in relation to practical activity of and in historically concrete social relations - this practical activity itself having 
been informed by theory that is continually modified and updated. This position is endorsed in the view of some of the critical theorists who remain inspirations to anthropologists, such as Antonio Gramsci (see Crehan 2002) and Raymond Williams (see Roseberry 1989). For example, Williams says in Keywords that theory 'is always in active relation to practice: an interaction between things done, things observed and (systematic) explanation of these', and, where praxis is 'a word intended to unite theory and with the strongest sense of practical (but not conventional or customary) activity: practice as action' (1976: 371, 318).

By nominating praxis in this way, applied anthropologists attempt to imbibe the notion of praxis as the application of theory while simultaneously obviating the Aristotelian dichotomy between theoretical knowledge and his concept of praxis to refer to practical knowledge (and acknowledging that not all praxis is the same - some is more 'free' than others). By emphasizing the creative action and agency of the people they learn from, even when these people are in the most determined of structural constraints, relatively disempowered and suffering from persistent inequalities, the applied anthropologist acknowledges movement in the system s/he studies, rather than assume static, conventional models of 'culture' or 'social structure'. Thus, it is not a deterministic processualism emphasizing entropy, but a view of the dynamism and power struggles inherent in historical change: 'Every praxis has two coordinates: one denotes the past, that which has been accomplished, the other the future onto which praxis opens and which it will create' (Lefebvre 1968: 55). Praxis since Kant at least has had the meaning of behaviour with ethical intent. Engaged anthropology (see Smith 1999) understands praxis as entailing political position-taking - 'praxis' was on the lips of a previous generation of applied scholars involved in 'participatory action research' (e.g., Fals-Borda 1979; Rahman 1985) and today's inspirational instigators of 'advocacy an- thropology' (e.g., Hale 2001, 2006, 2008) have reference to this concept - whether anthropology 'becomes at once the self-conscious study of humankind at the service of humankind' (Kozaitis 2000: 63) more generally, or whether it involves explicitly taking the sides of the marginalized and poor through explicit formulations such as 'community-centred praxis' (Singer 1994) and proposes and carries out interventions aimed at egalitarian solutions. As the sociologist Henri Lefebvre wrote, 'Revolutionary praxis introduces discontinuities into the overall socio-historical process' (1968: 52-3).

The articles in this special issue are prime examples of applied researchers engaging in praxis in the abovementioned guises as they formulate research strategies that focus upon the needs and interests of relatively disempowered members of communities involved in the tourist exchange. The authors track the creative and historically transformative - yet historically grounded and structured - practices of these communities and their individual members, while providing analyses designed to be at the service of those at the short ends of this exchange. In her article, Julie Scott shows how tourism's transformative potential is harnessed as a tool for overcoming deep-seated and protracted inter-communal divisions and structural violence. She reflects on the efforts of local actors, international organizations, the European Union, and applied anthropologists in Cyprus to use tourism projects to mitigate and mediate the inter-communal conflict between Turkish Cypriots of the unrecognized Turkish Republic of Northern Cyprus and Greek Cypriots. Scott was part of a development project that would have ostensibly created partnerships between Turkish and Greek Cypriots for the establishment of touristic enterprises. However, despite the utilization of anthropological insights in constructing networks of reciprocity between these groups, ultimately the success of the project was challenged by broken reciprocity, lack of trust and the weight of cultural constructions of differ- 
ence. At the same time, as Scott points out, the example is critical because even if a failure it suggests the conditions under which such plans might be allowed to function. Tourism on its own is not sufficient to cure all societal ills.

Wantanee Suntikul reports in her article on her involvement with a 'pro-poor' tourism development project in several villages in Viengxay, Laos. The project was designed to gauge (1) the villagers' current involvement with the nascent tourism industry, centred around a network of caves used by the local population and military outfits during the U.S.-Vietnam War, (2) the villagers' perception of tourism and tourists and their conceptions of the tourism exchange, and (3) the villagers' goals and fears regarding the future of tourism development in the area. With data obtained through focus-group encounters and ethnographic research and interviews, Suntikul shows how the villagers make sense of their encounters at least at first glance through the local cultural categories of reciprocity. She shows, however, that this is giving way to other forms of interaction as the relationships start to become charged with the air of commodification. It is a rare opportunity to see the formation of the personae of 'the toured', and to understand their motivations for engaging in the presentation of the tourism host self.

Stefan Michael Krause's article on surf tourism is informed by Krause's own experience his praxis - as a surfer. Here, the focus is shifted to the motivations and cultural constructs of the tourists themselves. Krause shows that for foreign surf tourists - and these are mainly from the United States - a trip to Costa Rica is a kind of pilgrimage, with the stages of separation, liminality and reintegration evident. He also shows how the surf tourists treat this as a rite of passage, emerging with life-changing experiences, what they describe as personal growth, therapy, escape and, perhaps not as directly, an enhanced status amongst their fellow surfers when they return to San Diego,
California or Cocoa Beach, Florida, or wherever they are from. Costa Rica and other surf tourism destinations welcome surf tourists because they are ostensibly 'low impact' tourists seeking out the 'authentic' local, exotic experience and shying away from over-developed tourist complexes with expensive beachfront hotels because they are at odds with the surfers' self-fashioning as rugged individualists. Krause suggests that surf tourism can, in fact, have seriously deleterious environmental and cultural effects because when local tourism resources are mobilized to attract and accommodate surf tourists, this sets in motion the kind of development in rural areas that ultimately make those areas unattractive to future surf tourists.

Finally, the article by Kevin A. Yelvington, Jason L. Simms and Elizabeth Murray on wine tourism in the Temecula Valley in southern California is a policy analysis of the state's role in promoting wine tourism as an engine of economic growth. The Temecula Valley is a relatively new and relatively small wineproducing region located between San Diego and Los Angeles. It receives tourists from the southern California conurbation who taste the award-winning wines in a bucolic rural setting - socially and culturally produced space, to be sure, to go with the socially and culturally constructed (but denied as such) 'Temecula terroir'. The article looks at the lacunae in the neoliberal state's development plans, showing how they assume endless supplies of the following: undocumented and vulnerable Mexican migrant farm labourers for the planned vineyard and winery development, the kind of environment that encourages wine tourism, which at the same time is threatened to be built out, and other natural resources, especially water, which is always a difficult political item in the U.S. southwest. The authors argue that applied interventions need to rest on no less than the critical theorization of the relationship between the state and civil society under postmodern capitalism. 
In all, these articles generate practical knowledge of the tourist encounter but in doing so also demonstrate the practical adequacy of theory. As a whole, they speak to disciplinary hierarchies within anthropology and allied social sciences where entrenched interests separate practice and application, on the one hand, and then theory production, on the other, and where these interests assign theory production to the 'prestige zones' of the discipline. This special issue undercuts this move if we acknowledge rather than hide the political and practical aspects that entail and imply theory. That is, the inseparability of theory and praxis. Thus, the special issue acknowledges and embraces the inherent political dimension in theory development that is for the most part denied and erased from the core of anthropological theory. To the contrary, it calls, instead, for an acknowledgment of the inseparability of theory, practice and praxis, and promotes the visibility of the political intent within praxis, and of praxis as the basis of the generation of anthropological knowledge. That is, theory must acknowledge its basis in the politics of praxis.

\section{Acknowledgments}

The ideas for this special issue were first developed in a panel titled 'Tourism: Applied Anthropological Interventions' at the conference of the Association of Social Anthropologists of the U.K. and Commonwealth, London, 10-13 April 2007. I benefitted from an International Travel Grant from the University of South Florida to be able to attend the conference and chair the panel. I would like to thank Jonathan Skinner, former editor of Anthropology in Action, for his encouragement for this special issue, and I would like to thank Christine McCourt, the editor, for her expert guidance, support and patience in the process of bringing this issue to publication. I would also like to thank the anonymous reviewers who read and commented upon the articles. I know the authors of the articles (and I am one) benefitted from their critical insight and helpful suggestions. And I would like to thank the authors themselves for their contributions to this special issue and to the debates in applied anthropology.

\section{References}

Crehan, K. A. F. (2002), Gramsci, Culture and Anthropology (Berkeley: University of California Press).

Fals Borda, O. (1979), 'Investigating Reality in Order to Transform It: The Colombian Experience', Dialectical Anthropology 4, no. 1: 33-55.

Gow, D. D. (1993), ‘Doubly Damned: Dealing with Power and Praxis in Development Anthropology', Human Organization 52, no. 4: 380-97.

Hale, C. R. (2001), 'What is Activist Research?', Items and Issues 2, nos. 1-2: 13-15.

Hale, C. R. (2006), 'Activist Research v. Cultural Critique: Indigenous Land Rights and the Contradictions of Politically Engaged Anthropology', Cultural Anthropology 21, no. 1: 96-120.

Hale, C. R. (ed.) (2008), Engaging Contradictions: Theory, Politics, and Methods of Activist Scholarship (Berkeley: Global, Area, and International Archive, University of California Press).

Kozaitis, K. A. (2000), ‘The Rise of Anthropological Praxis', in The Unity of Theory and Practice in Anthropology: Rebuilding a Fractured Synthesis, (ed.) C. E. Hill and M. L. Baba (Arlington, VA: American Anthropological Association), 45-66.

Lefebvre, H. (1968), The Sociology of Marx, (trans.) N. Guterman (New York: Pantheon Books).

Rahman, M. (1985), 'The Theory and Practice of Participatory Action Research', in The Challenge of Social Change, (ed.) O. Fals Borda (Beverly Hills, CA: Sage), 105-32.

Roseberry, W. (1989), Anthropologies and Histories (New Brunswick, NJ: Rutgers University Press).

Singer, M. (1994), 'Community-centered Praxis: Toward an Alternative Non-dominative Applied Anthropology', Human Organization 53, no. 4: 336-44.

Smith, G. (1999), Confronting the Present: Towards a Politically Engaged Anthropology (Oxford: Berg).

Warry, W. (1992), 'The Eleventh Thesis: Applied Anthropology as Praxis', Human Organization 51, no. 2: 155-63.

Williams, R. (1976), Keywords: A Vocabulary of Culture and Society (Oxford: Oxford University Press). 